\title{
Metadynamic recrystallization in C steels
}

\author{
A R MORGRIDGE \\ Mechanical Engineering Department, University of Ibadan, Ibadan, Nigeria
}

MS received 24 December 2001; revised 30 May 2002

\begin{abstract}
Metadynamic recrystallization has been investigated in three plain carbon steels (ENIA, EN2 and EN24) through the use of hot interrupted compression tests on a wedge plastometer. Holding time was $0.5 \mathrm{~s}$ between passes. Strain rates of $0 \cdot 05$ and $0 \cdot 12 / \mathrm{s}$ and small strain increments of 3,5 and $7 \%$ were employed. Test temperatures were varied between 800 and $1100^{\circ} \mathrm{C}$.

Various incremental and continuous stress strain curves were highlighted at different temperatures and strain rates for 3 steels, ENIA, EN2 and EN24, resulting in varying flow stresses and strains. Highest peak stress was $180 \mathrm{MPa}$ for $\mathrm{EN24}$ at peak strain of 0.25 and $900^{\circ} \mathrm{C}$, with a strain rate $0 \cdot 12 / \mathrm{s}$. Peak strain values for all steels at $1100^{\circ} \mathrm{C}$ was $0 \cdot 133$ at a strain rate of $0 \cdot 05 / \mathrm{s}$ and $0 \cdot 15$ at a strain rate of $0 \cdot 12 / \mathrm{s}$.

Strain accumulation resulted in dynamic and metadynamic recrystallization with refinement to about $15 \mu \mathrm{m}$ for dynamic and $22 \mu \mathrm{m}$ for metadynamic recrystallization. Fractional softening, $X$, decreased from $0 \cdot 27$ to 0.12 as recrystallization times in metadynamic recrystallization increased from $0.9 \mathrm{~s}$ to $1.5 \mathrm{~s}$ at $1100^{\circ} \mathrm{C}$. Time for $50 \%$ metadynamic recrystallization was also reduced as temperature increased.

For ENIA, a drop from $10000 \mathrm{~s}$ to $20 \mathrm{~s}$, as temperature increased from 800 to $1100{ }^{\circ} \mathrm{C}$ was observed. For EN24 and EN2 steels, a drop from $4000 \mathrm{~s}$ to $6 \mathrm{~s}$ for similar temperature rise was observed.

Metadynamic recrystallization (at strains higher than critical strain) is observed to be a strong function of strain rate and a very weak function of temperature and strain. It significantly refined the austenite grain size prior to transformation.
\end{abstract}

Keywords. Metadynamic recrystallization; C steels.

\section{Introduction}

When hot-rolling is carried out in plate-mills in the conventional rolling temperature range, the austenite $(\gamma)$ grains of slabs, coarsened at reheating, are considered generally to complete recrystallization during the time intervals between the reductions, and to be refined successively after every reduction. Although conventional rolling operations are finished at $1050-900^{\circ} \mathrm{C}$, this process continues after a reduction at $850-800^{\circ} \mathrm{C}$ in carbon-manganese or silicon-manganese steels, but stops after a reduction at $950-900^{\circ} \mathrm{C}$ in niobium-containing steels-which is about $100^{\circ} \mathrm{C}$ higher than in niobium-free steels. Convergence of grain refinement at the final stage of successive reductions is found both when the percentage reductions are held constant and when increased. $\gamma$ undergoes work-hardening, dynamic recovery and dynamic recrystallization corresponding to the amount of the deformation $(\varepsilon)$ and the Zener-Hollomon parameter $(Z)$ during hot-deformation with a constant strain rate. The microstructures produced by these processes are unstable. Furthermore, structural changes take place during holding at the test temperature, air-cooling from the test temperature and sometimes even during quenching after deformation. These static restoration processes after deformation are: (a) static recovery; (b) abnormal grain growth by strain-induced grain boundary migration; (c) classical static recrystallization; and (d) metadynamic or postdynamic recrystallization (Tamura et al 1988).

The observations by Djaic and Jonas (1973) indicate that abrupt changes in recrystallization time from straindependence to independence take place at changes in the strains a little smaller than $\varepsilon_{\mathrm{p}}\left(\varepsilon_{\mathrm{p}}\right.$ is the peak strain). The similar critical strains over which recrystallized grain sizes become independent to applied strain are also observed. Although these critical strains are, of course, smaller than the critical strains for the steady dynamic recrystallization, $\varepsilon_{\mathrm{s}}$, the recrystallization time and the recrystallized grain size are the same as those after straining over $\varepsilon_{\mathrm{s}}$. These abrupt changes correspond to the occurrence of metadynamic recrystallization without an incubation time and the critical strain may be related to the strain expected for the start of dynamic recrystallization, $\varepsilon_{\mathrm{c}}$. It arises because pre-existing recrystallization nuclei are present in the deformed structure by the onset of dynamic recrystallization as well as just after the straining over $\varepsilon_{\mathrm{s}}$. $\varepsilon_{\mathrm{s}}$ is around $0.7 \varepsilon_{\mathrm{p}}$, and Sellars (1979) reported that the critical strain in recrystallization is around $0.8 \varepsilon_{\mathrm{p}}$ and those in recrystallized grain size are a little greater than $0.8 \varepsilon_{\mathrm{p}}$. Sellars (1979) referred to the strain of the intersection over which the size of statically recrystallized grains becomes independent to applied strain, $\varepsilon^{*}$. 
Therefore, classical static recrystallization starts from a work-hardened and statically recovered structure after straining to the range from $\varepsilon_{\mathrm{cs}}$ to $\varepsilon_{\mathrm{c}}$, and metadynamic recrystallization occurs starting from the partly or steadily recrystallized structure by dynamic recrystallization after straining over $\varepsilon_{\mathrm{c}}$ or $\varepsilon^{*}$. If there is significant difference between $\varepsilon_{\mathrm{c}}$ and $\varepsilon^{*}$, classical static recrystallization and metadynamic recrystallization occurs side-byside after straining to the range from $\varepsilon_{\mathrm{c}}$ to $\varepsilon^{*}$. There is another interpretation, viz. that these two types of static crystallization occur respectively in the work-hardened part and in the dynamically recrystallized part after straining to the range from $\varepsilon_{\mathrm{c}}$ to $\varepsilon_{\mathrm{s}}$. The rate of metadynamic recrystallization is fast and sometimes it completes during quenching after deformation. It is a kind of static recrystallization, although it starts from a dynamically recrystallized structure. The grain structure is equiaxed and fairly uniform, has straight grain boundaries, and contains annealing twins, similar to the structure statically recrystallized by the nucleation and growth mechanisms but different from the dynamically recrystallized structure. The grain size in metadynamic recystallization is determined only by Zener-Hollomon parameter, Z. It is similar in size to the size of dynamically recrystallized grains, but slightly enlarged compared with it (McQueen and Bergerson 1979).

Dynamic, hence metadynamic recrystallization, does occur and contributes significantly to grain refinement in areas such as early roughing passes during hot rolling or in some hot forging extrusion processes.

Also in cases where holding times between applied strain do not allow for complete static recrystallization, total strain accumulation in previous passes is sufficient (Hodgson 1997).

The present work aims to analyse metadynamic recrystallization kinetics and resultant grain refinement in the three plain carbon steels chosen.

\section{Experimental}

ENIA, EN24 and EN2 steels were used as test materials in the experimental work. Cylindrical specimens were made (diameter $9.53 \mathrm{~mm}$, and $19.05 \mathrm{~mm}$ length). Appropriate high temperature lubricant was applied to both specimens and platens. These were put inside a container and heated to the testing temperature in an argon furnace.
When the testing temperature was reached, it was allowed to soak for $10 \mathrm{~min}$ and then the whole assembly was transferred to the compression chamber of the wedge plastometer. Uniaxial compression tests were performed in the plastometer between flat parallel platens and the position of a pair of symmetrically disposed wedges. Hydraulic valve and timing circuits enabled the movement to be performed in steps with control of speed, displacement and time interval between steps. Continuous measurements of compression and compressive force using a load-displacement ultraviolet (UV) recorder enabled the stress-strain characteristics to be determined.

Strain rates were varied between 0.05 and $0.12 \mathrm{~s}^{-1}$ and small strain increments of 3,5 and 7\% were applied. Test temperatures were varied between 800 and $1250^{\circ} \mathrm{C}$ for different materials. The wedge plastometer can apply several strain increments in simple compression with holding times adjustable between 0.11 and $4.6 \mathrm{~s}$. It also produced continuous stress strain curves and relaxation curves after straining. The stress strain curves provided experimental data for peak stress and peak strain values and the stress relaxation curves provided data for static, $t_{50}$ and metadynamic, $t_{50}$ values.

Detailed experimental results have been reported elsewhere (Morgridge 1990). Relevant results are included here for convenience. Composition of steels used is in table 1 .

Standard modelling equations in hot rolling were used to obtain calculated values of various metallurgical parameters and to compare such values with experimental values obtained.

\section{Results and discussion}

\subsection{Flow stress}

Flow stress is related to the Zener-Hollomon parameter by the equation (Lenard et al 1999)

$$
Z=\varepsilon^{\prime} \exp (Q / R T)=A[\sin h(\alpha \sigma)]^{n} .
$$

In figures 1 and 2, the continuous stress-strain curves exhibit region of static, dynamic and metadynamic recrystallization. Dynamic recrystallization records higher rolling loads than static recrystallization as dynamic recrystallization does not remove dislocation as effec-

Table 1. Composition of steels.

\begin{tabular}{|c|c|c|c|c|c|c|c|c|c|c|}
\hline \multirow[b]{2}{*}{ Steel } & \multicolumn{10}{|c|}{ Composition } \\
\hline & $\mathrm{C}[\%]$ & Si [\%] & $\mathrm{Mn}[\%]$ & $\mathrm{Nb}[\%]$ & $\mathrm{S}[\%]$ & $\mathrm{P}[\%]$ & $\mathrm{V}[\%]$ & $\mathrm{Cr}[\%]$ & $\mathrm{Ni}[\%]$ & Мo [\%] \\
\hline ENIA & $0 \cdot 12$ & $0 \cdot 10$ & 1 & & $0 \cdot 25$ & 0.07 & & & & \\
\hline EN24 & 0.4 & $0 \cdot 23$ & 0.55 & & 0.05 & $0 \cdot 05$ & & $1 \cdot 2$ & 1.5 & $0 \cdot 27$ \\
\hline EN2 & $0 \cdot 200$ & & $0 \cdot 80$ & & 0.06 & 0.06 & & & & \\
\hline
\end{tabular}


tively as static recrystallization. At low strain rates, low flow stress indicates low dislocation density and slow softening owing to low driving force and vice versa. Incremental stress strain curves (figures 1 and 2) depict variation of stress levels interrupted during holding times as exists in rod, strip, bar and plate rolling mills. The differences being in the amount of deformation strain, strain rates, interpass times and rolling temperatures. Deformation activation energy, $Q_{\text {def }}$, is $\sim 312-330 \mathrm{~kJ} /$ mol. Apparent activation energy for metadynamic recrystallization, $Q_{\text {app }}$ (mdrx) is $\sim 50 \mathrm{~kJ} / \mathrm{mol}$. Activation energy for both static and metadynamic recrystallization is $\sim 300 \mathrm{~kJ} / \mathrm{mol}$.

Figure 3 shows the variation of peak stresses with different temperatures and strain rates for ENIA steel. As expected, peak stresses reduced with increasing temperature but increased with increasing strain rate.
Similar trends can be observed for the 3 steels in figure 4 as Zener-Hollomon parameter, Z, increases. EN24 steel, however, exhibited a rise in peak stress for increasing strain rate, with the highest peak stress of $170 \mathrm{MPa}$ obtained at $900^{\circ} \mathrm{C}$, with a strain rate of $0.05 \mathrm{~s}^{-1}$. This could be due to the higher $\mathrm{C}$ content and traces of $\mathrm{Cr}, \mathrm{Ni}$ and $\mathrm{Mo}$ in this steel. Experimental values (table 2), of peak strain measured during tests are superimposed on calculated values in figure 5. For ENIA steel experimental values of 0.55 at $800^{\circ} \mathrm{C}, 0.05 / \mathrm{s}$ strain rate, and 0.2 at $1100^{\circ} \mathrm{C}$, $0 \cdot 05 / \mathrm{s}$ strain rate have been superimposed in the figure. Experimental values were higher than calculated ones but incremental trend was similar in both. The initial grain sizes in these steels are higher than the $50 \mu \mathrm{m}$ assumed for theoretical calculations. Similar trends have been observed by other authors (Sellars 1979; Hodgson 1997).

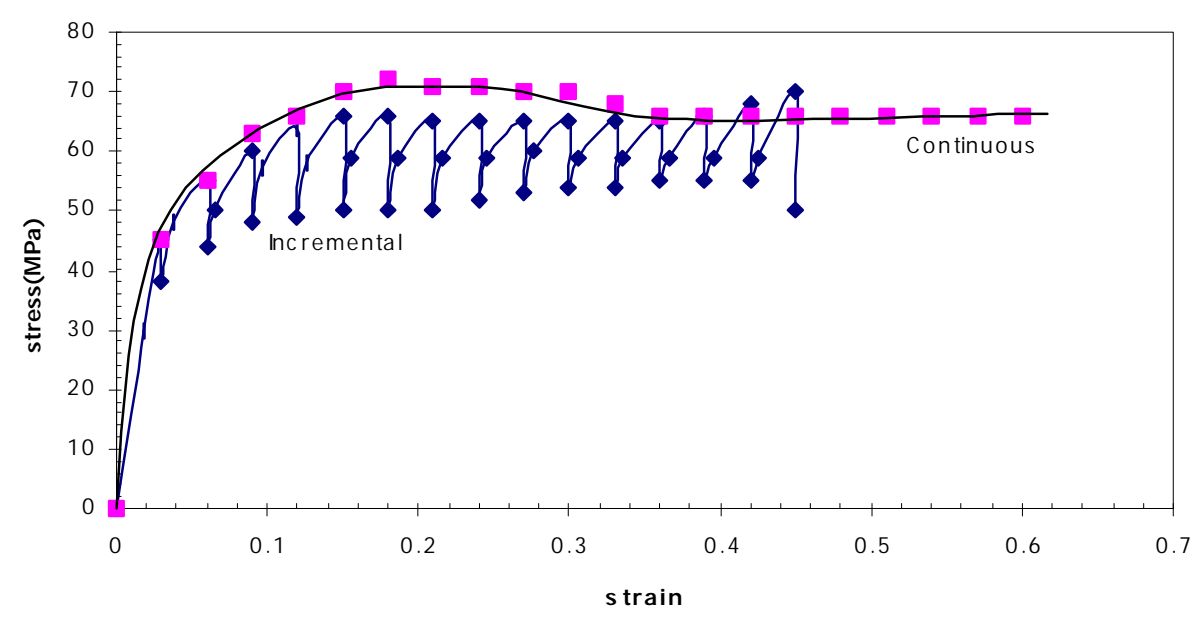

Figure 1. Incremental/continuous stress-strain curves, ENIA, $1100^{\circ} \mathrm{C}, 3 \%, 0.05 / \mathrm{s}, 0.5 \mathrm{~s} \mathrm{ht}$.

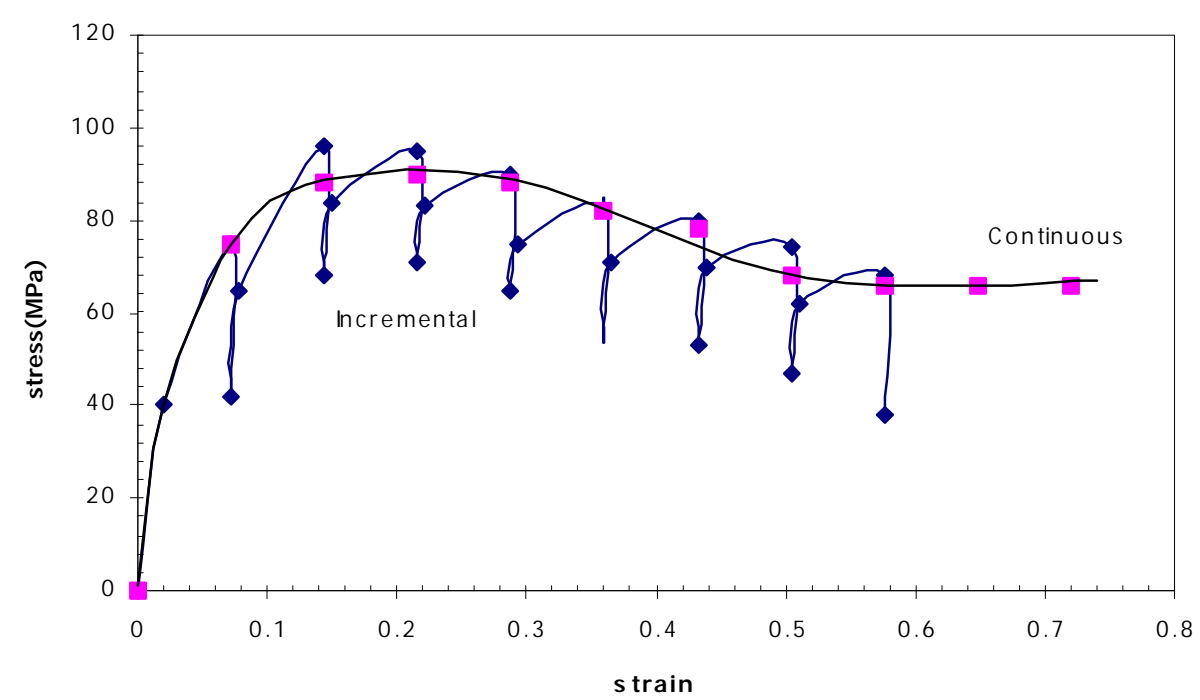

Figure 2. Incremental/continuous stress-strain curves, EN2, $1100^{\circ} \mathrm{C}, 7 \%, 0.5 \mathrm{~s}$ ht, $0 \cdot 05 / \mathrm{s}$. 


\subsection{Static softening $\left(X_{r e c}\right)$}

Holding time between passes was only $0.5 \mathrm{~s}$ as the tests were meant to simulate ring or rod rolling. From the calculated values of $t_{50}$ for three steels, with $50 \mu \mathrm{m}$ initial grain size, static $t_{50}$ was $24 \mathrm{~s}$ for ENIA at 0.051 strain and $6.05 \mathrm{~s}$ for EN2 and EN24 at 0.072 strain, with temperature at $1373 \mathrm{~K}$. Experimental $t_{50}$ values were $26 \mathrm{~s}$ and $9 \mathrm{~s}$, respectively for the same conditions. They are consistently higher than the theoretical ones. Using Avrami equation relating softening to $t_{50}$,

$$
X_{\text {rec }}=1-\exp \left\{-0 \cdot 639\left[t / t_{50 \%}\right]^{n}\right\}
$$

Calculated softening $(X=0.004$ for ENIA, and 0.025 for EN2 and EN24 steels at $1100^{\circ} \mathrm{C}$ ) is less than $10 \%$ for $0.5 \mathrm{~s}$ holding time and this is more likely to be recovery rather than recrystallization softening. For interrupted tests with large numbers of passes, strain will be retained at the end of each pass and total strain accumulation will exceed the critical strain needed for dynamic recrystallization to take place.

\subsection{Critical and peak strain $\left(\varepsilon_{p}\right)$}

Calculated peak strain values are shown in table 3 using Sellars (1979) equation,

$$
\varepsilon_{\mathrm{p}}=4.9 \times 10^{-4} \times d_{0} Z^{0.15},
$$

for $50 \mu \mathrm{m}$ initial grain size, and at different strain rates. Peak strain increased from 0.133 to 0.15 for all steels with increase in strain rate from $0 \cdot 05 /$ s to $0 \cdot 12 /$ s. These trends were evidenced in the stress-strain curves (figures $1-2)$, with experimental peak strain values.

Calculations using (Sellars 1979) equation and experimental values of peak strain for ENIA steel, are shown in figure 6 for increasing Z. Experimental values were slightly higher than calculated ones but both showed linear gradual increment with increasing $Z$. These trends have been widely reported (Djaic and Jonas 1973; Sellars 1979; Hodgson 1997).

\subsection{Accumulated strain}

Retained and accumulated strains can be calculated using equations:

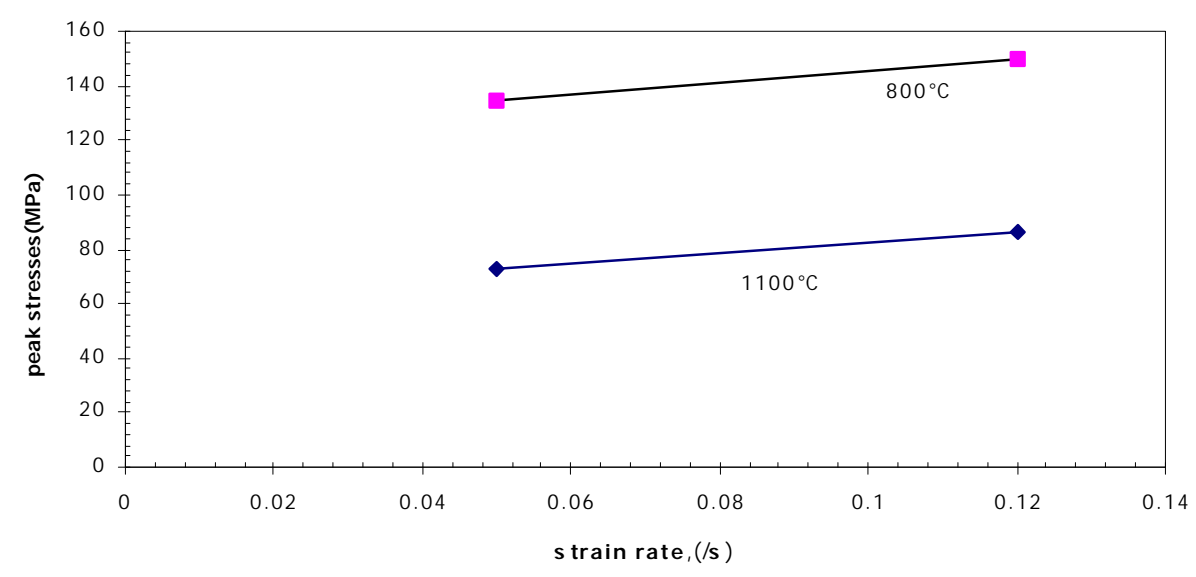

Figure 3. ENIA peak stresses at different temperatures and strain rates.

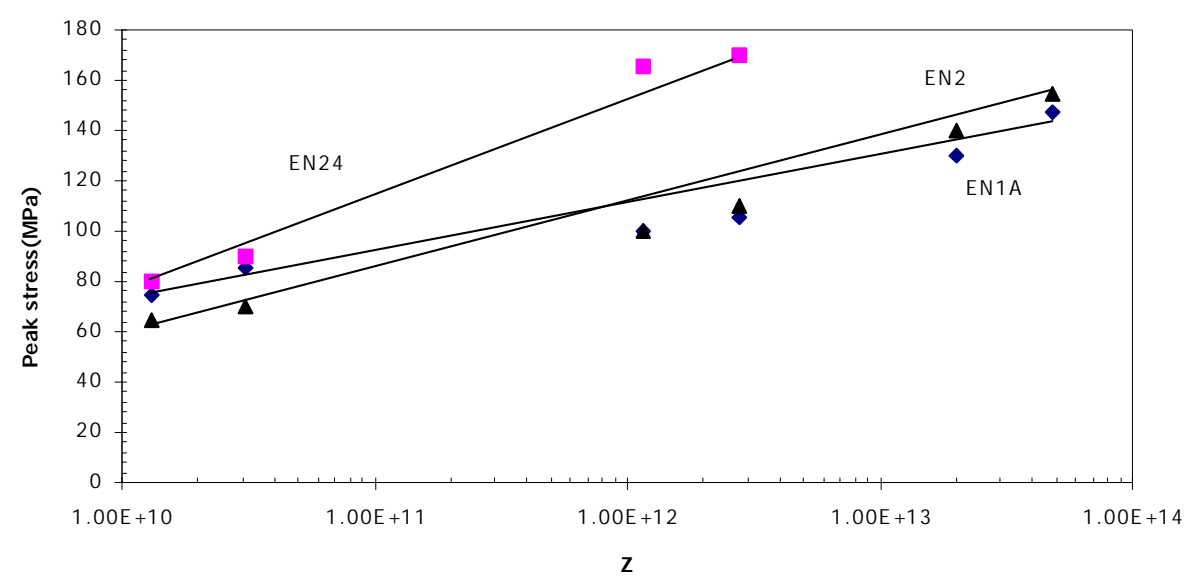

Figure 4. $\log (Z)$ vs peak stress for ENIA, EN2 and EN24 steels. 
(i) retained strain, $e_{\mathrm{r}}$ after $j$ th pass

$$
e_{\mathrm{r}}^{j}=e^{j}(1-x)
$$

and

(ii) total accumulated strain during jth pass

$$
E_{\mathrm{t}}^{j}=e_{\mathrm{r}}^{J+1}+e^{j} .
$$

When there is insufficient time for static recrystallization to take place between multiple passes, work hardening or 'strain' is accumulated from pass to pass until it attains and then exceeds the peak strain associated

Table 2. Summary of some experimental results.

\begin{tabular}{lrccc}
\hline Material & $\begin{array}{r}\text { Temp. } \\
\left({ }^{\circ} \mathrm{C}\right)\end{array}$ & $\begin{array}{c}\text { Strain rate } \\
(\mathrm{s})\end{array}$ & Peak strain & $\begin{array}{c}\text { Peak stress } \\
(\mathrm{MPa})\end{array}$ \\
\hline \multirow{4}{*}{ ENIA } & 800 & $0 \cdot 05$ & $0 \cdot 55$ & 120 \\
& 800 & $0 \cdot 05$ & $0 \cdot 55$ & 140 \\
& 800 & $0 \cdot 12$ & $0 \cdot 35$ & 145 \\
& 800 & $0 \cdot 12$ & $0 \cdot 35$ & 150 \\
& 1100 & $0 \cdot 05$ & $0 \cdot 2$ & 63 \\
& 1100 & $0 \cdot 05$ & $0 \cdot 2$ & 85 \\
& 1100 & $0 \cdot 12$ & $0 \cdot 25$ & 84 \\
& 1100 & $0 \cdot 12$ & $0 \cdot 3$ & 86 \\
& 900 & $0 \cdot 05$ & $0 \cdot 35$ & 160 \\
& 900 & $0 \cdot 05$ & $0 \cdot 45$ & 170 \\
& 900 & $0 \cdot 12$ & $0 \cdot 4$ & 160 \\
& 900 & $0 \cdot 12$ & $0 \cdot 25$ & 180 \\
& 1100 & $0 \cdot 05$ & $0 \cdot 15$ & 60 \\
& 1100 & $0 \cdot 05$ & $0 \cdot 15$ & 90 \\
& 1100 & $0 \cdot 12$ & $0 \cdot 25$ & 90 \\
& 1100 & $0 \cdot 12$ & $0 \cdot 25$ & 80 \\
& 800 & $0 \cdot 05$ & $0 \cdot 25$ & 135 \\
& 800 & $0 \cdot 05$ & $0 \cdot 25$ & 150 \\
& 800 & $0 \cdot 12$ & $0 \cdot 4$ & 150 \\
& 800 & $0 \cdot 12$ & $0 \cdot 35$ & 165 \\
& 1100 & $0 \cdot 05$ & $0 \cdot 2$ & 55 \\
& 1100 & $0 \cdot 05$ & $0 \cdot 2$ & 95 \\
& 1100 & $0 \cdot 12$ & $0 \cdot 5$ & 65 \\
& 1100 & $0 \cdot 12$ & $0 \cdot 4$ & 70 \\
\hline \multirow{4}{*}{ EN2 } & & & &
\end{tabular}

with the initiation of dynamic recrystallization. Also since interpass time is short, there can be no strain induced precipitation, hence no pancaking, so only dynamic recrystallization occurs. So interpass time is very crucial and determines what types of processes take place.

Dynamic recrystallization can take place below $T_{\mathrm{nr}}$ provided the interpass time is too short for strain induced precipitation to take place and hence also no pancaking. Strain accumulation is assumed to be under the uniform softening approach. This assumes that all grains behave homogeneously and the residual strain can be calculated from the recrystallized fraction, $X$.

At $1100^{\circ} \mathrm{C}, 0.5 \mathrm{~s}$ holding time, $0.05 / \mathrm{s}$ strain rate, softening $X$ for ENIA steel is 0.004. Retained strain, using equation above, at end of 1 st pass is 0.051 . Peak strain for ENIA for the same conditions is 0.2 (table 2) and dynamic recrystallization occurs at 0.8 of peak strain, which is $0 \cdot 16$. Retained strain at end of 3rd pass is $0 \cdot 153$. Therefore, dynamic recrystallization will occur at the start of 4th pass and metadynamic recrystallization at the start of 8th pass for ENIA steel.

For EN2 and EN24 steels, and same conditions as for ENIA steel, softening $X$ is 0.025 . Retained strain at end of 1 st pass is 0.07 . Peak strain, for same conditions, is $0 \cdot 2$ (table 2) and dynamic recrystallization occurs at $0 \cdot 8$ of peak strain, which is $0 \cdot 16$. Retained strain at end of 2nd pass is $0 \cdot 14$. Therefore, dynamic recrystallization will occur at beginning of the 3rd pass and metadynamic recrystallization at the beginning of 6 th pass for EN2 and EN24 steels.

\subsection{Dynamic softening $\left(X_{d y n}\right)$}

Increase in strain rate significantly reduces the recrystallization times for similar temperatures. Strain rates below $0 \cdot 01 / \mathrm{s}$ was avoided in these tests to avoid excessively low recrystallization rates due to low driving force. Hence, value of Avrami exponent 1.7 was used for metadynamic recrystallization. Avrami fits for softening

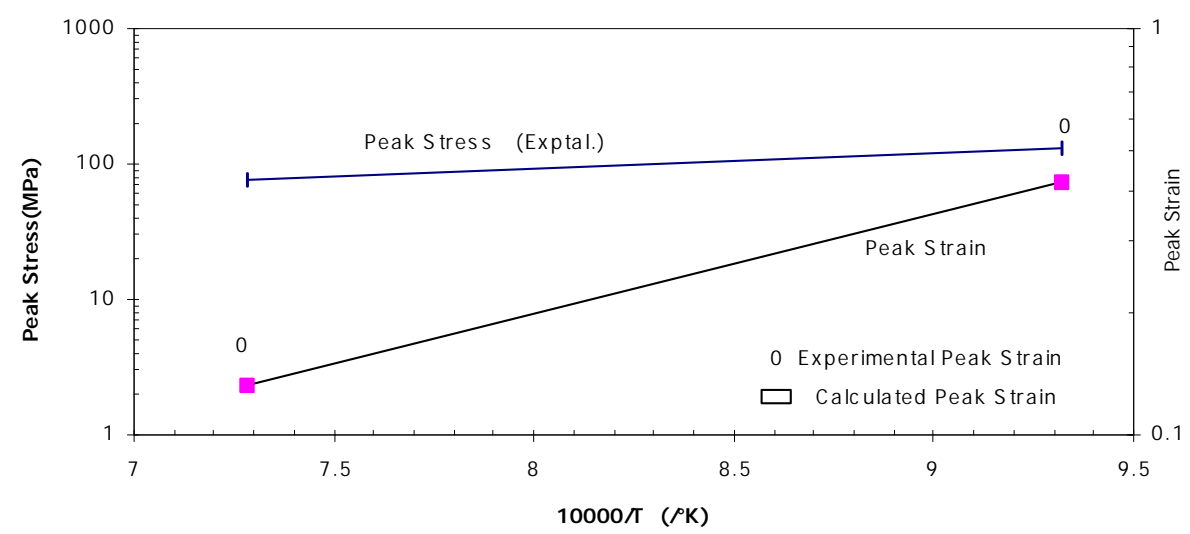

Figure 5. Peak stress/peak strain vs $10000 / T$ for ENIA steel at strain rate, 0.05/s. 
graphs showed that the value was accurate. Softening in the metadynamic recrystallization region is largely independent of temperature, strain and composition. Softening proceeds at much faster rate than in static recrystallization.

Figure 7 shows the metadynamic recrystallization kinetics for the 3 steels, using data from table 4. Holding time

Table 3. Summary of peak strain values for $50 \mu \mathrm{m}$ initial grain sizes and at different strain rates.

\begin{tabular}{llc}
\hline \multicolumn{3}{c}{ Peak strain values, $T=1373 \mathrm{~K}$} \\
\hline & \multicolumn{2}{c}{$50 \mu \mathrm{m}$} \\
\cline { 2 - 3 } Strain rates & ENIA & EN2 and EN24 \\
\hline $0 \cdot 05 / \mathrm{s}$ & $0 \cdot 133$ & $0 \cdot 133$ \\
$0 \cdot 12 / \mathrm{s}$ & $0 \cdot 15$ & 0.15 \\
\hline
\end{tabular}

was $0.5 \mathrm{~s}$. As expected, metadynamic recrystallization times were much smaller than the static times but increased with decrease in temperature. Fractional softening decreased from 0.27 to 0.126 for ENIA when temperature dropped from 1373 to $1073 \mathrm{~K}$ and recrystallization times increased correspondingly from $0.75 \mathrm{~s}$ to $1.25 \mathrm{~s}$.

Figure 8 extracted from Hodgson (1997) show such a similar trend in variation between fractional softening, $X$ and time for different temperatures. A rise from $0.07 \mathrm{~s}$ to $0.9 \mathrm{~s}$ recrystallization time, in the temperature range 900 $1200^{\circ} \mathrm{C}$ was accompanied by change in softening from $0 \cdot 1$ to 1 .

Figure 9 from Hodgson (1997) supports such a similar trend in variation between fractional softening, $X$ and time for different strain rates. As strain rate increased from $0 \cdot 03 / \mathrm{s}$ to $3 / \mathrm{s}$, a corresponding reduction in time from $10 \mathrm{~s}$ to $0 \cdot 1 \mathrm{~s}$ was observed for fractional softening $0 \cdot 5$.

The extracted figures show similar deductions as in the present work (Sellars 1979; Hodgson 1997).

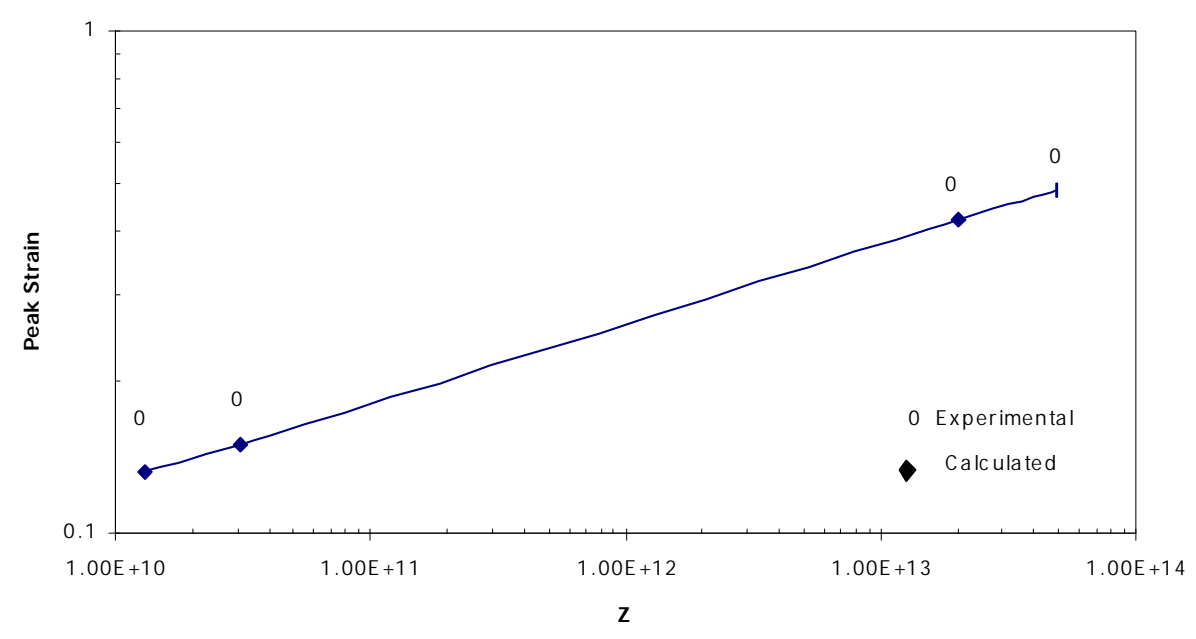

Figure 6. Peak strain vs $Z$ for ENIA steel.

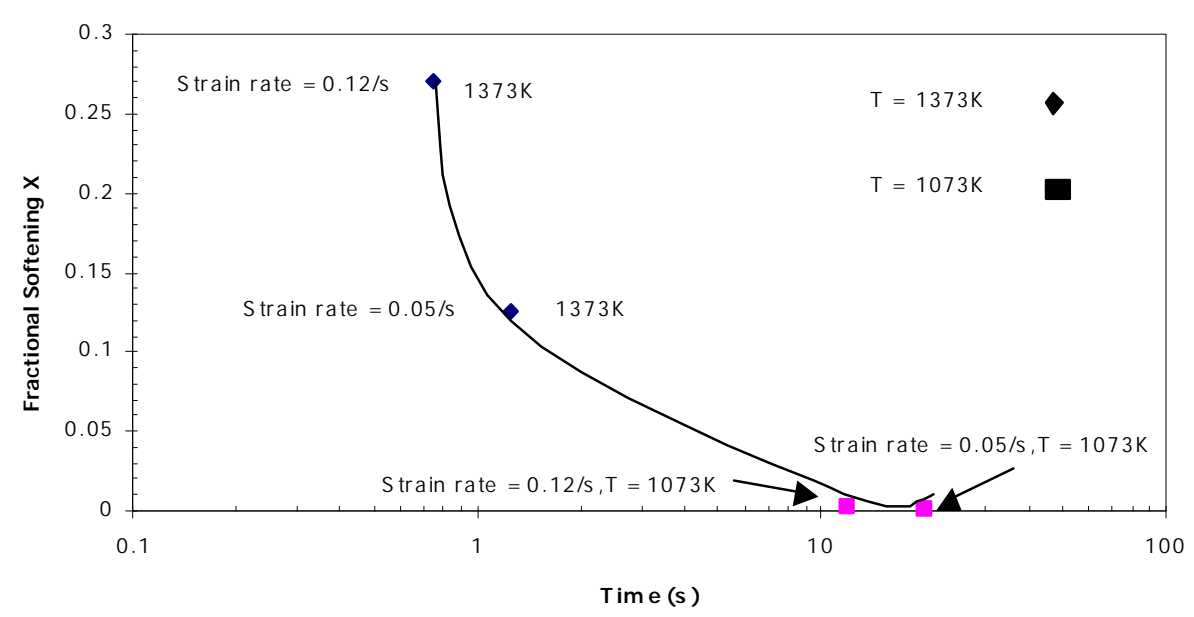

Figure 7. Metadynamic recrystallization kinetics for ENIA, EN2 and EN24 steels. 


\subsection{Dynamic recrystallization grain size $\left(d_{d y n}\right)$}

Dynamic recrystallization occurs in many hot deformation processes such as early roughing passes during hot rolling, or in some hot forging and extrusion processes and seam less tube rolling. $d_{\mathrm{dyn}}$ decreases with decreasing temperature and increasing strain rates. Initial grain size and strain has no effect. Dynamic recrystallization is related to strain rate and temperature by Sellars (1979) equation

$$
d_{\mathrm{dyn}}=1 \cdot 6 \cdot 10^{4} Z^{-0 \cdot 23} .
$$

Table 4. Summary of metadynamic softening $X$, for the 3 steels, at different temperatures and strain rates.

\begin{tabular}{|c|c|c|c|c|}
\hline \multirow{2}{*}{$\begin{array}{l}\text { Temperature } \\
(\mathrm{K})\end{array}$} & \multicolumn{2}{|c|}{ Strain rate $(0 \cdot 05 / \mathrm{s})$} & \multicolumn{2}{|c|}{ Strain rate $(0 \cdot 12 / \mathrm{s})$} \\
\hline & $t_{50 \text { meta }}$ & Softening, $X$ & $t_{50 \text { meta }}$ & Softening, $X$ \\
\hline 1073 & 19.9 & $0 \cdot 001$ & $11 \cdot 76$ & $0 \cdot 003$ \\
\hline 1373 & $1 \cdot 25$ & $0 \cdot 126$ & 0.75 & $0 \cdot 27$ \\
\hline
\end{tabular}

Since holding time between passes is only $0.5 \mathrm{~s}$ and static fractional softening, $X$ is less than $10 \%$, it is evident that strain will accumulate from pass to pass. Summary of the values of metadynamically recrystallized grain sizes are also given in table 5 for different strain rates. Calculations were made by using Sellars (1979) equation. Notice that strain rate has a very significant effect on these recrystallized grain sizes. $d_{\text {dyn }}$ for ENIA reduced from $72 \mu \mathrm{m}$ to $57 \mu \mathrm{m}$ as a result of increase in strain rate from $0 \cdot 05$ to $0 \cdot 12 / \mathrm{s}$. Metadynamic grain sizes were higher than dynamically recrystallized grain sizes since metadynamically recrystallized grains grow from existing dynamically formed nuclei without incubation time.

These trends are evident in figure 10 showing $d_{\text {dyn }}$ and metadynamically recrystallized grain sizes as functions of Zener-Hollomon parameter, $Z$. Notice the linear decline in grain size with increasing $Z$ values for both dynamic as well as metadynamic recrystallization.

Grain refinement in dynamic and metadynamic recrystallization has limitations but is better than static

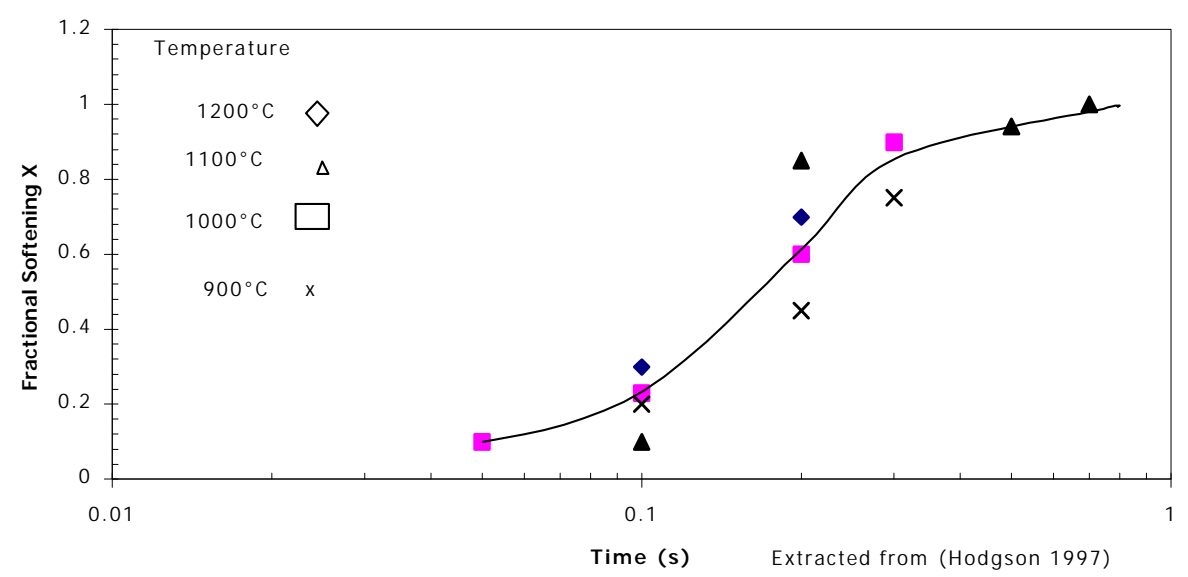

Figure 8. Metadynamic recrystallization kinetics of a $0 \cdot 04 \mathrm{C}-0 \cdot 3 \mathrm{Mn}$ steel after a rod mill simulation as a function of temperature.

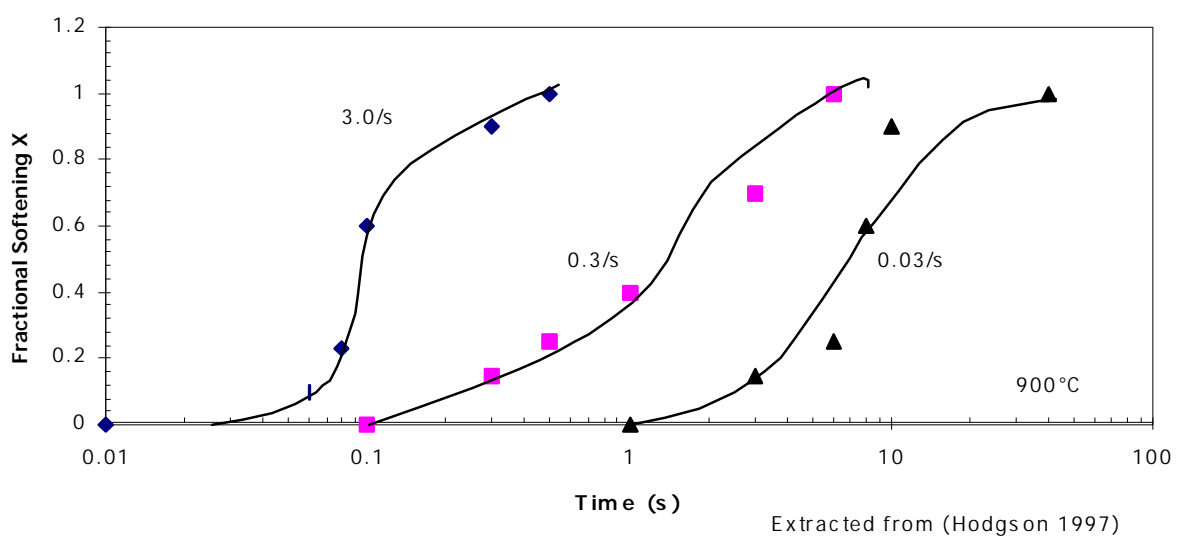

Figure 9. Metadynamic recrystallization kinetics of $0 \cdot 04 \mathrm{C}-0.3 \mathrm{Mn}$ steel after a rod mill simulation as a function of strain rate at $900^{\circ} \mathrm{C}$. 
recrystallization refinement. Higher strain rates also lead to better refinement in both dynamic and metadynamic recrystallization.

Figure 11 extracted from Hodgson (1997), shows such a similar trend in variation between grain size and ZenerHollomon, $Z$, for dynamic recrystallization. Metadynamic recrystallization occurred at higher values of $Z$ and had higher grain size values of around $10 \mu \mathrm{m}$ over those of dynamically recrystallized grain sizes.

Table 5. Summary of recrystallized grain sizes $\left(d_{\mathrm{dyn}}\right.$ and $d_{\text {meta }}$ ) for different strain rates.

\begin{tabular}{lccccc}
\hline & \multicolumn{2}{c}{$d_{\text {dyn }}$} & & \multicolumn{2}{c}{$d_{\text {meta }}$} \\
\cline { 2 - 3 } \cline { 5 - 6 }$T=1373 \mathrm{~K}$ & ENIA & $\begin{array}{c}\text { EN24 and } \\
\text { EN2 }\end{array}$ & & \multicolumn{3}{c}{ ENIA } & EN2 and \\
& & & & \\
\hline $0.05 / \mathrm{s}$ & 72 & 72 & & $125 \cdot 5$ & $125 \cdot 5$ \\
$0 \cdot 12 / \mathrm{s}$ & $57 \cdot 33$ & $57 \cdot 33$ & & 99.96 & 99.96 \\
\hline
\end{tabular}

\subsection{Metadynamic recrystallization time $\left(t_{50 \text { meta }}\right)$}

Figure 12 shows effect of temperature and strain rate on calculated metadynamic $t_{50}$. Exponent was 1.36 for both temperature and the three steels. Higher $t_{50}$ meta. were also obtained for lower finishing temperatures as expected. As strain is increased beyond the peak strain, $\varepsilon_{\mathrm{p}}$, strain no longer has significant effect on $t_{50}$ values. Between 0.051 and $\varepsilon_{\mathrm{p}}$ value of 0.2 , strain increments resulted in rapidly decreasing $t_{50}$ but strain rate has no effect. The reverse occurs beyond $\varepsilon_{\mathrm{p}}$. Sellars (1979) equation,

$$
t_{0.5}=1.06 \times 10^{-5} Z^{-0.6} \exp (300000 / R T),
$$

was used to calculate metadynamic $t_{50}$ values. When temperature is $1100^{\circ} \mathrm{C}$ and strain rate, $0.05 \mathrm{~s}^{-1}, t_{50}$ was $1.25 \mathrm{~s}$. $t_{50}$, however, was $0.75 \mathrm{~s}$ for all 3 steels at strain rate of $0.12 \mathrm{~s}^{-1}$. For the same conditions, experimental values for metadynamic $t_{50}$ were 1.53 and $1.04 \mathrm{~s}$, respec-

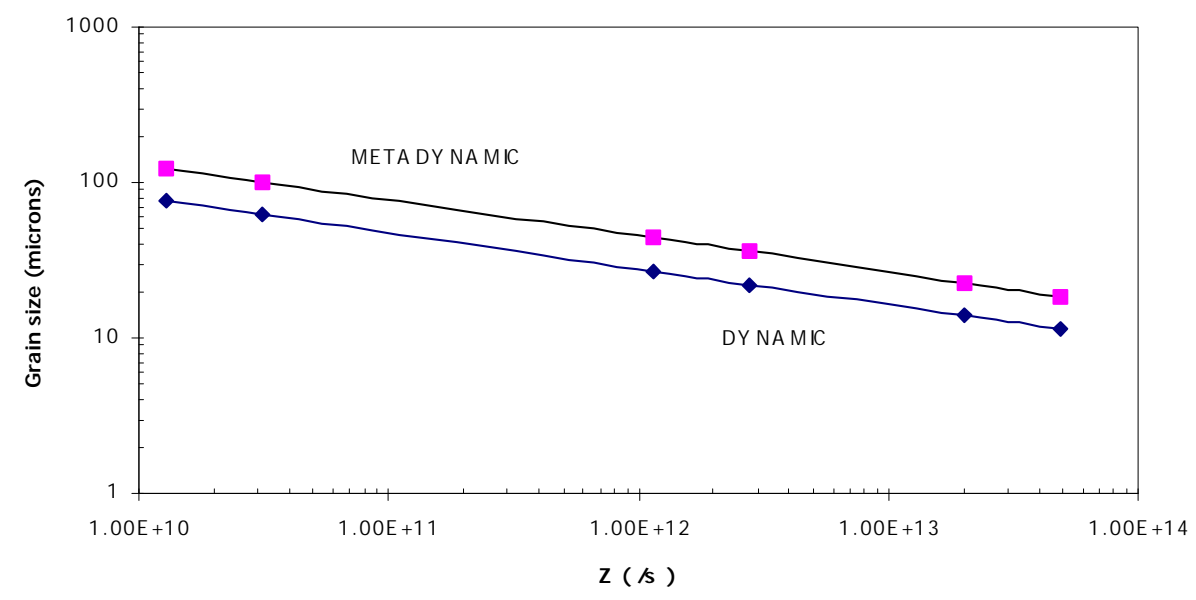

Figure 10. Dynamically and metadynamically recrystallized grain sizes as functions of Zener-Hollomon parameter.

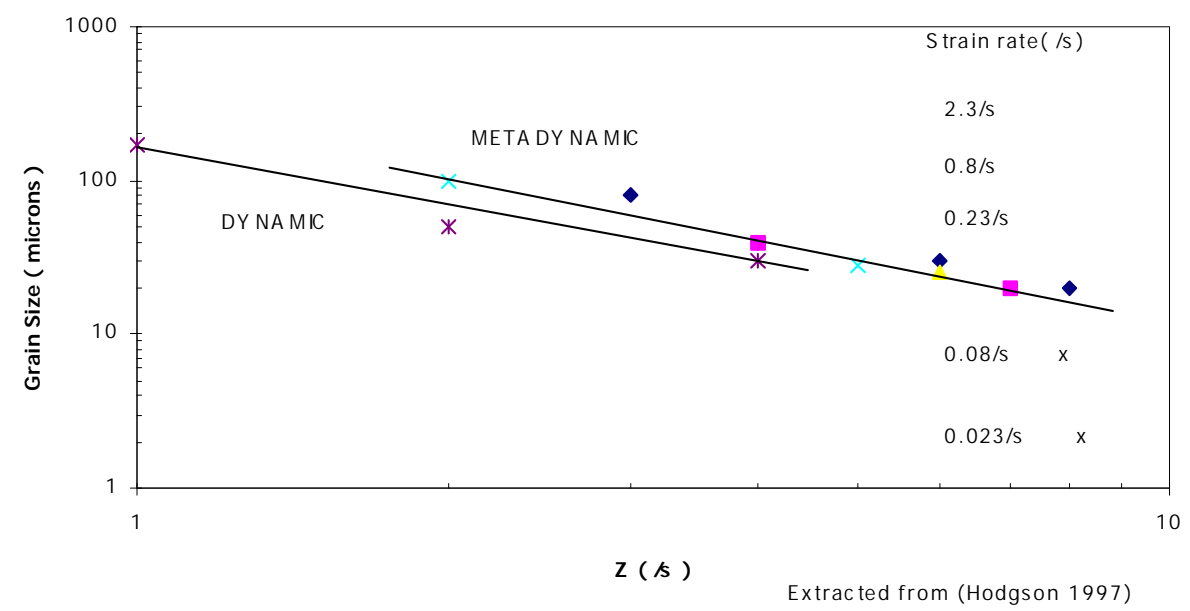

Figure 11. Dynamically and metadynamically recrystallized grain sizes as functions of Zener-Hollomon parameter. 


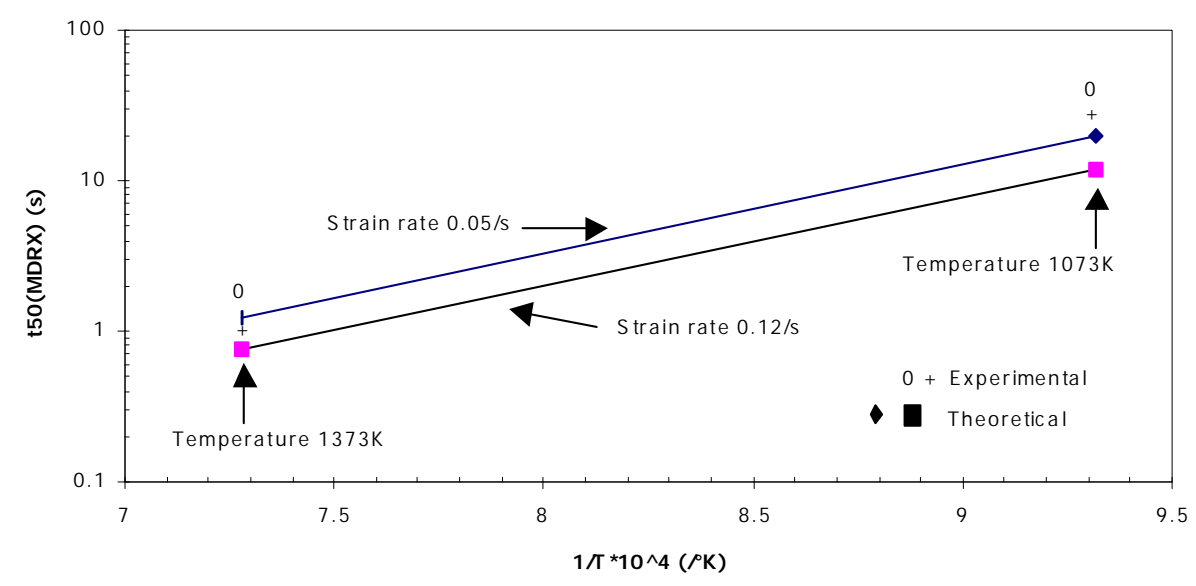

Figure 12. Effect of temperature and strain rate on the metadynamic $t_{50}$ for ENIA, EN2 and EN24 steels.

tively. At $800^{\circ} \mathrm{C}$, however, experimental metadynamic $t_{50}$ was $14 \mathrm{~s}$ at $0 \cdot 05 / \mathrm{s}$ strain rate and $11.2 \mathrm{~s}$ at $0 \cdot 12 / \mathrm{s}$ strain rate. These experimental values have been inserted in figure 12 above for comparison. They are consistently higher than the theoretical ones.

It was found that the rate of softening was largely independent of temperature (figures 7 and 12), a strong function of strain rate (figure 9) and a weak function of composition (Hodgson 1997) (figures 7 and 12), although the weak composition dependence probably only exists at high temperatures. This is quite the opposite from static recrystallization where the rate of recrystallization in austenite is primarily affected by temperature, strain, and grain size with little effect from strain rate. Similar reasoning have been deduced by other authors (Sellars 1979; Hodgson 1997).

\section{Conclusions}

(I) Metadynamic recrystallization (at strains higher than critical strain) displayed strong function of strain rate and very weak function of temperature and strain.

(II) It significantly refined austenite grain size prior to transformation.

(III) Avrami exponent of 1.7 was used for metadynamic recrystallization.

(IV) Strain rate of less than $0 \cdot 01 \mathrm{~s}^{-1}$ was avoided during experimentation, to ensure complete softening under prevailing metadynamic conditions.

\section{Acknowledgement}

My sincere thanks to the Materials Engineering Laboratory, Mechanical Engineering Department, University of Oulu, Finland, for the provision of complete fellowship and research facilities.

\section{References}

Djaic R A P and Jonas J J 1973 Metall. Trans. 4621

Hodgson P D 1997 The metadynamic recrystallization of steels, THERMEC'97, International conference on thermomechanical processing of steels and other materials (eds) T Chandra and T Sakai (Wollongong: The Minerals, Metals \& Materials Society) pp 121-131

Lenard J G, Pietrzyk M and Cser L 1999 Mathematical and physical simulation of the properties of hot rolled products (Amsterdam: Elsevier Publications) pp 150-166

McQueen H J and Bergerson S 1979 Metal Soc. J. 625

Morgridge A R 1990 Study of yield behaviour of metals during incremental compression tests, under hot working conditions, using a wedge plastometer (Australia: Materials Forum) 14 pp 20-26

Sellars C M 1979 The physical metallurgy of hot working and forming processes (eds) CM Sellars and G J Davies (London: The Metals Society) pp 3-15

Tamura I, Ouchi C, Tanaka T and Sekine H 1988 Thermomechanical processing of high strength low alloy steels (London: Butterworths Publications) pp 49-53 